\title{
Raíces populares y cultura de masas en la nueva narrativa hispanoamericana
}

FERNANDO AÍNSA

UNESCO

En el momento de abordar la narrativa latinoamericana de las últimas décadas, una comprobación que puede parecer obvia se impone. Los años no han pasado en vano.

En efecto, a partir de fines de los años setenta se han ido atenuando los extremos inaugurados por las vanguardias experimentales en lo estético y los radicalismos revolucionarios en lo político y se ha abandonado la vocación totalizante y totalizadora que caracterizó las grandes «empresas ficcionales» de los años sesenta. A diferencia de las novelas que pretendían ser verdaderas summas en lo existencial y fenomenológico, la ficción reciente tiene aspiraciones en apariencia más modestas, lejos de la «gran novela neo-romántica-fenomenológica, con algo de poema metafisicos de que hablaba, no sin cierta presunción, Ernesto Sábato y en la cual debían reconocerse los atributos de la narración, de la epopeya y de la poesía.

El proceso es ahora más sutil y se caracteriza por la irónica desconfianza con la que se recapitulan las proclamas inauguradas con entusiasmo y rotundidad en los años sesenta. Muchos mitos se han desacralizado, la simplificación maniquea y el maximalismo voluntarista han cedido a una mayor ambigüedad y a un revisionismo de posiciones y actitudes propias y ajenas. Se anuncia así la emergencia de una nueva ficción en abierta ruptura con los esquemas de «héroes y víctimas») de décadas anteriores, cuando no declarando un abierto parricidio con las armas de la irrisión, el humor, la ironía, la parodia y el grotesco. El intenso revisionismo anuncia, al mismo tiempo, una desprejuiciada apertura al mundo.

En la mayoria de los casos, ha sido a través de la desenvoltura lúdica, la capacidad de auto-denigración, la conciencia de la relatividad histórica desde 
la cual se proyecta un destino auténtico y en la distancia con que se miran los propios reflejos en un espejo deformante que la nueva ficción aborda la realidad. En esas obras se adivina el rumbo de una narrativa cuyas reivindicaciones tradicionales parecen haber sido desmentidas por la historia a la que se aborda desde una perspectiva más modesta, en todo caso aceptando su intrínseca complejidad y preconizando una voraz integración antropológica del rico acervo cultural del continente. Así se decantan formalismos y recuperan expresiones culturales marginadas u olvidadas; se reactualizan géneros y modalidades de sub-géneros que estuvieron en el origen de las formas «modernas» de la narrativa, como parábolas, crónicas, baladas, apólogos, romances, folletines y hasta "novelas por entregas» donde no siempre se distingue con claridad lo que es literatura popular, cuando no comercial, de la llamada literatura «literaria».

En general, el estilo de esta nueva ficción es más clásico y menos barroco, más atenido a la narratividad que a la experimentación formal, donde las estructuras internas son menos visibles y se privilegia el argumento, la «historia» con minúscula y el testimonio vital más entrañable. Buena parte de esta producción elige como estilo un realismo descriptivo, cuando no testimonial, en el que pueden reconocerse sin dificultad los lectores. A nuevas realidades socio-culturales se responde con nuevos realismos literarios.

La nueva ficción no ofrece «catálogos» de técnicas narrativas, al modo del ostentoso andamiaje de Mario Vargas Llosa en La casa verde o de Carlos Fuentes en Cambio de piel, o no practica la experimentación lingüística en que se han solazado Néstor Sánchez en sus elaboradas ficciones «novo-romanescas», Salvador Elizondo en sus frías «construcciones ficcionales» y el primer Juan José Saer en El limonero real (1974); Nadie nada nunca (1980), La Mayor (1982) y La ocasión (1988).

Y si lo hacen, como Guillermo Cabrera Infante o Héctor Libertella (desde El camino de los hiperbóreos, 1968, hasta El paseo internacional del perverso, 1986) es para incorporar a la fiesta de la lengua, giros y expresiones populares presentes en diálogos callejeros, referencias intertextuales y fragmentarias de todo tipo, slogans publicitarios y letras de canciones, citas literarias y filmográficas. Ello explica la recuperación, a través de nuevas formulaciones estéticas, de la oralidad, del imaginario popular y colectivo presente en mitos y tradiciones, pero también en la integración de expresiones de la cultura popular y de la cultura de masas con las cuales mantiene un abierto diálogo intertextual. 


\section{Novelas al ritmo del chá-chá-chá}

El cine, el teatro, el teleteatro, incluso el circo (Los dos payasos (1995) de César Aira), la música de corridos, tangos y boleros, salsa y chá-chá-chá, deportes como el fútbol, el ciclismo y hasta el tenis, proveen de temas a una narrativa, buena parte de cuyos códigos y referentes provienen de estos repertorios culturales, cuyos «lenguajes» han sido incorporados con naturalidad a cuentos y novelas. No escapa a esta integración antropológica el propio arte culinario, cuyos secretos y recetas no sólo demuestran ser novelescas en Como agua para chocolate de la mexicana Laura Esquivel, sino también buenas «recetas comerciales» como lo prueba el éxito de ventas de Afrodita de Isabel Allende.

Nos interesa en estas páginas subrayar, justamente, esta incorporación de tópicos, temas, preocupaciones y argumentos de la cultura popular a un patrimonio literario que se enriquece día a día gracias a los variados componentes que animan este nuevo paisaje. Los mitos en que se condensa —cine, televisión, fútbol, música, etc.- y los héroes que la representan -idolos, actores, cantantes y compositores- son materia para una ficción que los consagra o los degrada, en todo caso, que los tiene en cuenta.

Esta es empresa de más de una generación. Ya lo había adelantado Gustavo Sainz en su novela Gazapo (1965), donde el ritmo sincopado de la música y el lenguaje de los jóvenes sustituyó el costumbrismo realista de notas sociologizantes de décadas anteriores, y lo han ratificado otros, como es el caso reciente del chileno Alberto Fuguet en Sobredosis (1989) y Mala onda, con la incorporación de la cultura del zapping de imágenes televisivas, realidades virtuales, video-clips y otros fragmentos y residuos de la post-modenidad.

De igual modo, el desenfadado realismo urbano del mexicano Guillermo Samperio, gracias al cual se denuncian las características de la cultura cotidiana construida con fragmentos de publicidad, música, cine y periodismo, se explicita en la desenvoltura y el humor de Miedo ambiente y otros miedos (1977) y Gente de la ciudad (1986). Mordaz, irónico, burlón, exorcizando los riesgos del realismo a partir de una conjuración de sus peores estereotipos, estas obras - y esta no es su única paradoja- desacralizan mitos a través de su integración a la literatura, justificando nuevos sueños y esperanzas. Sátira de la publicidad que reitera el colombiano Héctor Sánchez en Entre ruinas (1984).

En todo caso, se trata, como propone el portorriqueño Luis Rafael Sánchez, a modo de advertencia sobre «el método del discurso» que guía su 
novelización de la vida del cantor de boleros Daniel Santos, de evitar que «el olor documental despiste los usos de la fantasía). Así, temas de tangos y boleros se incorporan a sus obras La guaracha del macho camacho (1976) y La importancia de llamarse Daniel Santos (1988) no sólo como parte de la intertextualidad en que la literatura reconoce las expresiones de la cultura musical, sino como un verdadero canto a la vida. «La vida es una cosa fenomenal», dice el estribillo de la famosa guaracha y nos repite a modo de letanía Sánchez en cl barroco torrencial de sus personajes con «cara de víveme y tócame». La novela de la «jacarandosa y pimentosa, laxante y edificante, profiláctica y didáctica, filosófica y pegajosófica guaracha del Macho Camacho La vida es una cosa fenomenal», se prolonga en las "verdades del texto» sobre la vida del famoso Daniel Santos, construida a partir de fragmentos de "geografias», letras de canciones y nombres conocidos de una historia de la que todo el resto son «oleajes alucinatorios», es decir, «invención», lo que el autor llama cuna narración_hibrida y fronteriza, mestiza y exenta de las regulaciones genéricas». Los ritmos caribeños están también presentes en las obras de los venezolanos Salvador Garmendia (El inquirto avacobero) y en Ángel Gustavo Infante (Soy la rumba). Por algo nos dice Luis Barrera Linares que En el bar la vida es más sabrosa. Lisandro Otero, por su parte, retraza en Bolero (1986) las glorias y adversidades de Esteban María Galán, artista cubano intérprete de ritmos populares que decidió conquistar la Habana entre los años 40 y los 50, cuando el ritmo del bolero cautivaba el continente.

Los tres relatos de Delito por bailar cha-cha-cha (1995) de Guillermo Cabrera Infante, especialmente el bolero en «En una mujer que se ahoga», en la historia del chachachá que da título al libro, reiteran esta temática donde la música está presente o subyace, incluso en las interrupciones de la anodina música Muzak o en la experimental atonal. Eruditos estudios acompañan esta implosión del bolero en la ficción, lo que refleja la Fenomenología del bolero de Rafael Castillo Zapata.

No es sólo el Caribe el que transforma la música en una rítmica y sugerente textualidad de cuentos y novelas, sino que el chileno Hernán Rivera Letelier (1950), autor de Himno del ángel parado en una pata (1996), hace de rancheras y corridos mexicanos, el leit-motiv de La Reina Isabel cantaba rancheras (1994), novela situada en el mundo de las salitreras del norte de Chile. Música de fondo mexicana en el burdel chileno que escenifica y donde no suenan extrañas sus notas, tan impregnadas y familiares resultan esos ritmos en el alma de todo el continente. 
Ritmos que no tienen fronteras de géneros. El uruguayo Roberto Echavarren, reconocido como poeta, aborda en Ave Roc una suerte de biografia novelada del famoso cantante de rock, Jim Morrison, cuyo estilo de música y de vida encarnó el espíritu de los años sesenta. Utilizando el símbolo del pájaro mítico Ave Roc del libro Simbad el Marino, capaz de trasponer los límites más extremos, el autor dirige una larga carta a Jim desde un ubicuo «aqui». En realidad, confunde el «tú» de su misiva con lo que podría ser la primera persona de un narrador que se identifica con su personajes. Echevarren lo utiliza como medio para ensalzar los «estilos discrepantes» de lo que llama las "guerras de estilo» que arruinaron el consenso de las costumbres de aquellos años que evoca sin nostalgia, aunque sea a partir de una profunda experiencia vital.

Por su parte, el tango que sirvió, a través de los epígrafes de textos de Alfredo de la Pera, para dividir los capítulos de Boquitas pintadas (1968) de Manuel Puig, reaparece con sus fueros de significativa cultura popular en buena parte de la obra de Pedro Orgambide. En su reciente Cuentos con tangos (1998) dice con ironía que «Ahora me vienen a buscar porque el tango está de moda", un modo de recordar que es el autor de Historias con tangos $y$ corridos (1976), de los ensayos Yo, argentino (1968) y de Gardel y la patria del mito (1985), donde definió una verdadera tipología de músicos y cantores del género, cuya actualidad se confirma día a día con el renovado entusiasmo popular que suscita el tango en el Río de la Plata.

Un realismo que se alimenta de la nostalgia, es cierto, pero también de una mitografia que ha encontrado en el cine una de sus fuentes. Si Guillermo Cabrera Infante ha hecho del lenguaje cinematográfico, de sus mitos fundacionales y del universo de héroes e ídolos forjados en el siglo XX un referente obligatorio de su creación, ha sido Manuel Puig, desde La traición de Rita Hayworth, quien ha hecho de la función formativa y "deformativa» del cine un uso novelesco que ha reiterado en los relatos de su libro póstumo Los ojos de Greta Garbo (1993). A partir de un close-up a las películas fundadoras, como Pan, amor y fantasia protagonizada por Gina Lollobrigida, despliega una mirada nostálgica a los que fueron los mitos de su infancia y de buena parte de los escritores nacidos a partir de los cuarenta. Para otros, como para el colombiano Germán Santamaría, el mito cinematográfico es Marylin Monroe. En ¿Marylin? (1974), una prostituta apodada la Marylin, iniciada en ferias, habla con naturalidad de «la feona de María Félix», de Lana Turner y se siente halagada por su macró cuando le asegura «Mamita tú eres la Monroe y yo soy Pedro Armendáriz». 
Actores favoritos de toda una generación - Charles Chaplin, Laurel y Hardy, John Wayne y Jane Fonda - circulan con naturalidad en Triste, solitario y final (1973) de Osvaldo Soriano. Un mito del cine tan presente que Alicia Borinsky, exploradora de otros tópicos populares en sus novelas Mina cruel y Sueños del seductor abandonado (1995) a la que define como unovela vodevils, lo hace suyo desde el título de su último libro de relatos, Cine continuado, escrito bajo la advertencia al lector «Vistámonos para ir al cine (Te daré besitos en la oscuridad...) my y que divide en capítulos titulados con fragmentos de letras de boleros ( Reloj detén tu camino...); "Tanto tiempo disfrutamos este amor...») y de tangos («Acaso te llamaras simplemente María...».

Continuidad cinematográfica entre la vida real y la ficción, influencias de un género y sus mitos sobre personajes y conductas que reitera el personaje de Por favor, rebobinar de Alberto Fuguet que pasa su vida viendo películas norteamericanas. No en balde el propio Fuguet señala que su mayor influencia literaria ha sido Woody Allen.

\section{Las «canchas» deportivas de la literatura}

Cultura de masas y mitos contemporáneos que no excluyen la pasión por el fútbol. Deporte popular, representativo por excelencia de los espectáculos de multitudes, el fútbol es ahora tema de numerosos cuentos y novelas, especialmente en los países con intensa tradición futbolística. Si se puede hablar de una verdadera «moda mitologizadora», hay que recordar que en el cuento «El puntero izquierdo», narrado en primera persona y utilizando la jerga popular, Mario Benedetti ya había abordado en Montevideanos (1961) los códigos culturales de un «hombre gol» a quien se intenta comprar para que pierda un partido clave. En este relato el mensaje es claro: la condición de jugador nato, aunque al principio se deje pasar «la globa entre las piernas como a cualquier gilberto"s, triunfa sobre toda consideración espúrea de «jugador comprado». Así, cuando le «viene el sarampión»-y contra lo esperado- el puntero izquierdo «hace un gol de apuro», gol que marca el triunfo y gol que restablece la dignidad de un deporte que por algo fascina a las multitudes. Su condición dramática y literaria está en la tensión y esa dimensión de protagonismo, antagonismo y confrontación que provoca.

Pese al antecedente de Mario Benedetti, en la actualidad puede hablarse de una mayor comunicación entre fútbol y literatura y hasta de una verdade- 
ra «mitomanía» que ha ido superando las mutuas desconfianzas ideológicas entre intelectuales y deportistas, esa "distancia irónica» de la que habla Manuel Vázquez Montalbán ${ }^{1}$, desde la cual los hombres de letras vivían los «espectáculos de masas». Transformado ahora en la teorización estética del juego mismo y el «sistema de signos» que encarna - como sugería Pier Paolo Pasolini- donde la fantasía, la imaginación, la improvisación y el talento del jugador se expresan en el marco teórico de las reglas que lo rigen, el fútbol se ha legitimado en la literatura.

Con palabras directas, Eduardo Galeano afirma en El fútbol a sol y sombra —esa especie de tipología de la cultura del fútbol a través de textos breves sobre los diferentes protagonistas del espectáculo (arquero, árbitro, hincha, fanático, etc.) - que «los hinchas somos inocentes, inocentes incluso de las porquerias del profesionalismo, la compra y la venta de los hombres y las emociones». Irónico y mordaz, Galeano asegura que «el árbitro es arbitrario por definición» y que el arquero, condenado a ser «un solo» y «a mirar al partido de lejos», mientras espera "su fusilamiento», tiene por única misión impedir que se hagan goles (los que son «la fiesta del fútbol»). Por lo tanto, su misión es ser el «aguafiestas» de los partidos.

«La tremenda soledad de un golero», ese ver el juego a la distancia, la escasa participación en el partido del cual es el último obstáculo frente al cual no puede contar con nadie, es justamente el tema de La sonrisa del golero (1997) de Carlos Bañales. A través del testimonio de los integrantes de una típica barra de amigos en un barrio de Montevideo, se recrea el espiritu de la amistad varonil que anima a un grupo de hombres estrechamente ligados por una solidaridad deportiva que supervive a través de los años, alrededor del golero Lino envuelto siempre en un shalo patético» de contenida emoción. «Durante los siete años que duró la hermandad de barrio hecha de esta y algunas otras pocas cosas por el estilo, fueron y vinieron muchos botijas por el vecindario, pero solamente nosotros cuatro estuvimos allí todo el tiempo, todos los años de la escuela y hasta mediados de los liceales. Éramos una barra dentro de la barra que iba cambiando con el tiempo». El fútbol, visto desde ese extremo, esa frontera que marca el arco, adquiere en esta novela una dimensión inesperada de emocionada afección. Se idealiza así, como en el poema de Héctor Negro esa condición de «Un remanso de tierra, con luz de cualquier cielo,/ un pájaro redondo, para

1 Coloquio «Fútbol y artes», Cuadernos Hispanoamericanos, Madrid, n. * 581, 1998. 
poder jugar,/ dos arcos de madera o de ropa y un revuelo/ de alucinados chicos que parecen bailary.

Una «barra» de amigos algo diferente, pero no menos significativa, es la de los «veteranos» (mayores de treinta y cinco años) exiliados chilenos de Orange County en California, que deciden integrar un equipo de fútbol gracias a la iniciativa de un viejo entrenador, Don Eusebio, y jugar partidos de «descuento» en un campeonato que resulta muy dificil de organizar. Con humor, Juan Villegas en Las seductoras de Orange County (1989) reconstruye con nostalgia los signos de una amistad que el fútbol ayuda a mantener en un medio - los Estados Unidos- donde ese deporte resulta tan indiferente y «extranjero» como lo son los propios jugadores.

Isaac Goldemberg en Tiempo al tiempo (1984) narra la vida de Marquitos Karushansky como si fuera la transmisión de un partido en el Estadio Nacional de Lima. En el «narrador-locutor», en el ritmo ansioso de una voz que pauta exaltada los episodios que han marcado su vida desde la circuncisión inicial, el lector reconoce las expresiones y modismos de un estilo deportivo radiofónico, apenas interrumpido por anuncios publicitarios, glosas y apostillas personales. Con ingenio se proyecta la derrota y la imposibilidad de "ganar" de un protagonista que, como el héroe de La vida a plazos de Jacobo Lerner (1978), está condenado desde su nacimiento a ser un «perdedor».

Del fútbol espectáculo al fútbol fuente y vínculo de amistad, la rica panoplia temática de un deporte vivido como experiencia, reaparece en la reciente antología Cuentos de fútbol argentino (1997) seleccionada y prologada por el humorista Roberto Fontanarrosa, donde se recogen relatos de Osvaldo Soriano, Héctor Libertella, Elvio Gandolfo, Marcelo Cohen, Humberto Constantini, Guillermo Saccomanno, Luisa Valenzuela y otros. Esta antologia demuestra que el interés por este deporte no se limita a los clásicos aficionados, a quienes gritan desde las tribunas o siguen por la radio y la televisión los partidos que comentan en bares y oficinas, sino que también se vive en las «canchas de la literatura».

"Cuando la forma del mundo/ que rebota/ se va a esconder en la trampa de la red/como pelota/ te alcanza que la tarde quede ronca/ para olvidarte de la mufa/ y de la bronca» - ha poetizado Roberto Santoro, epígrafe que utiliza Reynaldo Harguinteguy en La redondez de la tierra (1995), divertidos e informados ensayos breves sin pretensiones trascendentes, donde transmite los sentimientos y pasiones que el fútbol concita en el espíritu popular y en el vasto mundo de los aficionados, desde su nacimiento en la «calle, con $\mathrm{C}$ 
de cuna», a «La novela del mundial», pasando por los tópicos de la «mensa sana in corpore sano» y "goles son amores» y el reino de «futbolandia» y los divertidos «otra cosa es con guitarra», «la grande partita» y «creer o reventars.

Por su parte, el mexicano Guillermo Samperio nos cuenta en el relato «Lenin en el fútbol» (Miedo ambiente, 1978), cómo las ideas sindicales que el protagonista ha leído en un «libro de Lenin» tratan de aplicarse en un equipo de fútbol. La experiencia es desastrosa, porque nadie puede admitir que haya "balompiecistas de izquierda».

El fútbol puede ser el excelente telón de fondo en cuyo primer plano se desarrolla otro drama: el de la represión política. Antonio del Masetto en Hay unos tipos abajo (1998) utiliza el momento del Mundial de 1978 en Argentina, para recordar el sórdido transfondo de miedo y opresión que se vivia en las calles en plena dictadura de Videla. Al modo de la película Un día particular que protagonizaran Marcelo Mastroiani y Sofia Loren, Pablo, el protagonista de la novela de Masetto, vive los ecos de las ovaciones del estadio donde se consagran los goles del triunfo del campeonato, encerrado en su apartamento y temiendo por su vida, esquizofrenia en la que estuvo sumergido el país entero.

Lo mismo sucede con la influencia de las historietas, esos personajes de comics que ya son parte del imaginario popular y de la formación literaria de los jóvenes escritores. Francisco Massiani en El llanero solitario tiene la cabeza pelada como un cepillo de dientes (1975), convierte al Llanero Solitario en el Pelón, apodo que da a un jugador de fútbol en un relato donde la crueldad de un grupo de adolescentes se transforma en verdadera ceremonia de iniciación.

A estas canchas de la literatura se incorporan las del tenis. Basta pensar en la novela La velocidad del amor (Match Ball, 1989) de Antonio Skármeta, donde la pasión por este deporte elitista en su origen y hoy espectáculo de multitudes, se equipara con el amor imposible de un "veterano» al borde de la vejez por una joven campeona. Canchas que son también las del boxeo en los relatos de Osvaldo Soriano y en Gatica (1991) de Enrique Medina, sobre el famoso boxeador José María Gatica, y cuya primera parte se titula gráficamente: «Segundos afuera».

El ciclismo no puede faltar en este inventario deportivo-literario. Difundido y practicado con entusiasmo en Colombia, el ciclismo es el eje central de la patética reconstrucción de la vida y el triste final de un campeón, Teléforo Numas, que retraza Héctor Sánchez en Sin nada entre las manos (1976). 
«Las bicicletas no reculan. No. No rugen, no. Ruedan sí, sobre los aros cuando el hombre trabaja el molinete», nos dice metafóricamente, para recordarnos más adelante: «Violinista que no pulsara su instrumento a diario, nunca llegaría a concertista. Pianista que igual dejaba pasar los días en blanco, tampoco sería llevado a concierto. La constancia era la base de toda empresa. Hombre sin disciplina, hombre perdido. En el ciclismo habia que permanecer no sólo todo el día practicando, sino soñar, comer, descansar, bañarse, todo girando a su alrededor».

\section{La cultura exhibicionista de las playas}

En este rápido panorama de los nuevos «tajos» en la realidad que abordan los escritores, no puede omitirse uno de los escenarios privilegiados para intercambiar experiencias no sin un cierto exhibicionismo: la playa.

La cultura de la playa, esa cultura generada en el espacio de encuentro y convergencia social que reaparece con escasas variantes a lo largo de la costa de las islas a todo lo largo del continente latinoamericano, de Acapulco y Varadero a Punta del Este y Mar del Plata, es reivindicado como topos del paraíso y lánguida ensoñación utópica por Edgardo Rodríguez Juliá en El cruce de la bahia de Guánica (1989) y en Verano (1993) de Kalman Barsy. Esta última ritualiza los veranos como expresión de una repetición de códigos y señales que se intercambian tos salvavidas de un balneario- - Solimarcon el recién llegado, Cacho, «rastrillador» de las sucias arenas de la playa. Universo cerrado, aunque abierto, la playa recibe e incorpora cíclicamente, al ritmo de las estaciones del año, a sus visitantes. Construida como la paradigmática novela de Cesare Pavese, La playa, o como una película neo-realista italiana de los cincuenta, la obra de Barsy repertoria los tópicos de un escenario que hasta no hace mucho estaba ausente del paisaje narrativo. Y cuando lo hizo cn la década del sesenta en un país como Uruguay, cuya cultura playera es proverbial, con obras como Trajano de Sylvia Lago, Tan solos en el balneario de Jorge Musto y tantas otras, fueron recibidas con ostensible resistencia. Mario Benedetti anunció con alarma la llegada de una «literatura de balneariom.

Viajero en otras playas del continente de las que conoce sus respectivas mitologías, Rodríguez Juliá, por su parte, descubre en las de su Puerto Rico natal la condensada representación de las clases sociales del país, «sus clanes, sectores y submundos, su extranjería y marginalidad, también sus modas, 
sin olvidar esos lugares preferidos de donde parte y a donde llega toda travesía: la imaginación y la memoria». La «polifonía barroca» de toda sociedad se encuentra a lo largo de estas playas adonde se vuelcan los diferentes grupos que Rodríguez Juliá describe con minucia etnológica no exenta de afectuosa complicidad. En su atento paseo costero desfilan tipos y tópicos y se adivina tras la evocación sentimental, la comprobación de lo "penosamente kitsch» de esas imágenes de los trópicos dignos de una tarjeta postal. Una imagen que puede ser también la de la pintura de Rafael Ferrer que el escritor nos presenta como «otro» punto de vista posible para un mismo paisaje. El «deseo» en todas sus variantes de apetencia ensalza las playas como espacios hacia los que toda la ciudad gravita, hasta convertirlas en símbolos de una sexualidad hecha de miradas cruzadas sobre cuerpos desnudos, pieles tersas dorándose al sol y vellos mecidos por la brisa. Playas emblemáticas de Puerto Rico, pero también de Rio Janeiro, donde a través de la distraída somnolencia de sus ojos entrecerrados, Rodriguez Juliá vive Copacabana como un placentero escenario donde la literatura se descubre sin complejos en la vida cotidiana, pero donde, sobre todo, se redescubre la dimensión del ser humano.

Esta parece ser la característica más importante de la nueva narrativa latinoamericana: buscar sin solemnidad al individuo, a hombres y mujeres en su dimensión más auténtica, perdidos entre las ruinas de una historia desmantelada por la retórica y la mentira, y al encontrarlos, descubrirlos y ensalzarlos, para justificar nuevos sueños y espetanzas. Y todo ello, aunque el personaje creado parezca inventado, aunque en definitiva lo sea.

\section{BIBLIOGRAFÍA BÁSICA}

Borinsky, Alicia. Cine continuado, Buenos Aires, Corregidor, 1997.

Barsy, Kalman. Verano, Bogotá, Norma, 1993.

Goldemberg, Isaac. Tiempo al tiempo, Hannover, Ediciones del Norte, 1984.

Harguinteguy, Reynaldo. La redondez de la tierra, París, Alzieu Editor, 1995.

Massiani, Francisco. El llanero solitario tiene la cabeza pelada como un cepillo de dientes, Caracas, Monte Ávila, 1975.

Otero, Lisandro. Bolero, La Habana, Letras Cubana, 1986. 
Rodríguez Juliá, Edgardo. El cruce de la Bahia Guánica, San Juan de Puerto Rico, Editorial Cultural, 1989.

Samperio, Guillermo. Miedo ambiente, México, SEP, 1986.

Sánchez, Luis Rafael. La guaracha del macho camacho, Buenos Aires, Ediciones de la Flor, 1976.

Villegas, Juan. Las seductoras de Orange County, Madrid, Libertarias, 1989. 